\title{
Pengaruh Model Pembelajaran Berbasis Proyek Terhadap Hasil Belajar IPA Siswa Kelas VII SMP Advent Tondano
}

\author{
Buarno Refualu ${ }^{1 *}$, Ni Wayan Suriani ${ }^{2}$ \\ 1,2Jurusan Pendidikan IPA, FMIPA, Universitas Negeri Manado \\ "e-mail: buarnorefualu23@gmail.com
}

\begin{abstract}
Abstrak. Penelitian ini bertujuan untuk mengetahui pengaruh model pembelajaran berbasis proyek terhadap peningkatan hasil belajar IPA pada siswa kelas VII SMP. Rancangan penelitian yang digunakan adalah desain eksperimental semu yaitu posttest control group design. Sampel penelitian terdiri dari dua kelas yakni kelas VIIA berjumlah 18 siswa (kelas eksperimen) dan kelas VIIB berjumlah 18 siswa (kelas kontrol) sehingga total jumlah keseluruhan sampel penelitian adalah 36 orang. Hasil penelitian menunjukkan bahwa thitung $=5,063>t_{\text {tabel }}=2,050$. Berdasarkan kriteria pengujian, jika thitung lebih besar dari $t_{\text {tabel }}\left(t_{\text {hitung }}>t_{\text {tabel }}\right.$ ) maka $\mathrm{H}_{0}$ ditolak yang berarti $\mathrm{H}_{\mathrm{a}}$ diterima yang artinya rata-rata skor hasil belajar IPA siswa yang diajar dengan model pembelajaran berbasis proyek lebih tinggi dibandingkan rata-rata hasil belajar IPA siswa yang diajar tanpa model pembelajaran berbasis proyek. Sehingga, dapat disimpulkan bahwa terdapat pengaruh model pembelajaran berbasis proyek terhadap peningkatan hasil belajar IPA siswa di SMP Advent Tondano.
\end{abstract}

Kata kunci: model pembelajaran berbasis proyek, hasil belajar IPA

\begin{abstract}
This study aims to determine the effect of project-based learning model on improving science learning outcomes in grade VII junior high school students. The research design used was a quasi-experimental design, namely the posttest control group design. The research sample consisted of two classes, namely class VIIA with 18 students (experimental class) and class VIIB with 18 students (control class) so that the total number of research samples was 36 people. The results showed that $t_{\text {count }}=5.063>t_{\text {table }}=$ 2.050. Based on the test criteria, if $t_{\text {count }}$ is greater than $t_{\text {table }}\left(t_{\text {count }}>t_{\text {table }}\right)$ then $H_{0}$ is rejected, which means $H_{a}$ is accepted, which means that the average science learning outcome score of students who are taught using project-based learning models is higher than the average science learning outcome of students who are taught using project-based learning models. taught without a project-based learning model. Thus, it can be concluded that there is an effect of the project-based learning model on improving science learning outcomes students at SMP Advent Tondano.
\end{abstract}

Keywords: project based learning model, science learning outcomes

Diterima 10 Januari 2021 | Disetujui 21 Juni 2021 | Diterbitkan 30 Juni 2021

\section{PENDAHULUAN}

Hasil observasi yang ditemukan pada siswa Kelas VII di SMP Advent Tondano ditemukan beberapa permasalahan, diantaranya kurangnya motivasi dan perhatian siswa dalam belajar IPA, guru lebih sering menggunakan metode ceramah dalam pembelajaran sehingga siswa lebih memilih aktivitas lain dalam kelas dan banyak siswa yang mengantuk ketika pembelajaran berlangsung, yang berdampak pada rendahnya hasil belajar pada mata pelajaran IPA siswa kelas VII di SMP Advent Tondano.

Rendahnya hasil belajar siswa tersebut kemungkinan karena kurangnya pemahaman siswa terhadap konsepkonsep dari materi yang diajarkan. Selain itu, guru lebih sering 
menggunakan metode ceramah dalam pembelajaran IPA, sehingga siswa hanya sebatas mendengarkan, memperhatikan materi pelajaran yang diterangkan serta mengerjakan tugas yang diberikan oleh guru. Pembelajaran seperti ini dapat membatasi siswa dalam menuangkan ide, gagasan dan kreatifitas siswa dalam pembelajaran. Keadaan ini menyebabkan siswa lebih cepat bosan dalam mengikuti proses pembelajaran. Untuk mengatasi masalah tersebut diharapkan guru dapat memilih dan melakukan inovasi pembelajaran yang tepat dalam kegiatan pembelajaran, sehingga siswa dapat dengan aktif dalam belajar serta tujuan pendidikan dapat tercapai. Hal ini dapat dilakukan dengan cara penerapan pembelajaran yang tidak lagi berpusat pada guru, tetapi lebih menjadikan guru sebagai fasilitator. Salah satu metode pembelajaran yang dirasa tepat untuk diterapkan yaitu model pembelajaran berbasis proyek.

Model pembelajaran berbasis proyek dapat menstimulasi motivasi, proses dan meningkatkan prestasi belajar siswa menggunakan masalah-masalah yang berkaitan dengan materi tertentu pada situasi nyata (Rais dalam Amanda, Subagia \& Tika, 2014).

Pembelajaran berbasis proyek merupakan model pembelajaran yang tergolong dalam kategori pembelajaran aktif (Tumewu, Wulan \& Sanjaya, 2017). Secara sederhana pembelajaran berbasis proyek didefinisikan sebagai suatu pengajaran yang mencoba mengaitkan antara teknologi dengan masalah kehidupan sehari-hari yang akrab dengan siswa, atau dengan proyek sekolah. Masalah yang diberikan dalam pembelajaran berbasis proyek merupakan suatu konteks bagi siswa untuk belajar tentang cara berpikir kritis dan keterampilan pemecahan masalah serta memperoleh pengetahuan dan konsep yang esensial dari materi pelajaran agar penguasaan materi meningkat dan siswa mampu mencapai hasil belajar optimal maka pada proses pemecahan masalah siswa dapat bertukar pendapat dan bekerjasama dengan teman kelompoknya (Rati, Kusmaryatni \& Rediani, 2017).
Pembelajaran berbasis proyek merupakan model pembelajaran yang berpusat pada siswa unutk melakukan suatu investigasi yang mendalam terhadap suatu topik. Siswa secara konstruktif melakukan pendalaman pembelajaran dengan pendekatan berbasis riset terhadap permasalahan dan pertanyaan yang berbobot, nyata, dan relevan (Grant, 2002).

Pembelajaran berbasis proyek juga merupakan strategi belajar mengajar yang melibatkan siswa untuk mengerjakan sebuah proyek yang bermanfaat untuk menyelesaikan permasalahan masyarakat atau lingkungan. Permasalahan yang dikaji merupakan permasalahan yang kompleks dan membutuhkan penguasaan berbagai konsep atau materi pelajaran dalam upaya penyelesaian. Proyek yang dibuat dapat merupakan proyek dari satu guru, atau proyek bersama dari beberapa guru yang mengasuh pelajaran yang berbeda. Siswa dilatih untuk melakukan analisis terhadap permasalahan, kemudian melakukan eksplorasi,mengumpulkan informasi, interprestasi, dan penilaian dalam mengerjakan proyek yang terkait dengan permasalahan yang dikaji (Sani, 2014).

Penerapan model pembelajaran berbasis proyek dengan efisien dan efektif dalam pembelajaran materi pencemaran lingkungan dapat meningkatkan hasil belajar IPA.

Hasil belajar adalah hasil dari suatu interaksi tindak belajar dan mengajar. Perubahan sebagai hasil proses belajar mengajar dapat ditunjukkan dalam berbagai bentuk seperti, pengetahuan, pemahaman, dan sikap. Hasil belajar menjadi tolak ukur untuk menentukan keberhasilan siswa dalam memahami suatu materi pelajaran, dimana hasil belajar ini dapat berupa keterampilan, nilai dan sikap setelah siswa mengalami proses belajar (Dimyati \& Mudjiono, 2006).

Oleh karena itu, penelitian ini bertujuan untuk mengetahui pengaruh model pembelajaran berbasis proyek terhadap peningkatan hasil belajar IPA 
pada siswa kelas VII di SMP Advent Tondano.

\section{METODE PENELITIAN}

Penelitian ini dilaksanakan di SMP Advent Tondano dan waktu penelitian selama 1 bulan dengan frekuensi tiga kali pertemuan dalam satu minggu.

Rancangan penelitian yang digunakan adalah desain eksperimental semu yakni posttest control group design, dimana terdapat kelompok eksperimen dan kelompok kontrol (Sugiyono, 2011).

Sampel penelitian adalah keseluruhan jumlah populasi yang terdiri dari dua kelas yakni kelas VIIA berjumlah 18 siswa (kelas eksperimen) dan kelas VIIB berjumlah 18 siswa (kelas kontrol) sehingga total jumlah keseluruhan sampel penelitian adalah 36 orang siswa. Teknik analisis data penelitian menggunakan statistik uji-t sampel berpasangan related dengan taraf nyata $a=0,05$.

\section{HASIL DAN PEMBAHASAN} Hasil Penelitian

Data hasil belajar IPA kelompok eksperimen (kelas VIIA) menunjukkan bahwa skor tertinggi adalah 95 dan skor terendah 75. Berdasarkan data tersebut juga didapatkan harga rata-rata 85 dan simpangan baku 5,94. Distribusi frekuensi data variabel hasil belajar IPA kelompok eksperimen disajikan dalam Tabel 1, sedangkan histogramnya dapat dilihat pada Gambar 1.

Tabel 1. Distribusi frekuensi data hasil belajar IPA siswa kelompok eksperimen

\begin{tabular}{lllll}
\hline \multirow{2}{*}{ Kelas } & $\begin{array}{l}\text { Interval } \\
\text { kelas }\end{array}$ & $\begin{array}{l}\text { Batas } \\
\text { kelas }\end{array}$ & $\begin{array}{l}\text { Frekuensi } \\
\text { absolut }\end{array}$ & $\begin{array}{l}\text { Frekuensi } \\
\text { relatif }\end{array}$ \\
\hline 1 & $75-79$ & 74,5 & 2 & 11,11 \\
2 & $80-84$ & 79,5 & 4 & 22,22 \\
3 & $85-89$ & 84,5 & 6 & 33,33 \\
4 & $90-94$ & 89,5 & 4 & 22,22 \\
5 & $95-99$ & 94,5 & 2 & 11,11 \\
\hline Jumlah & & & 18 & $100 \%$ \\
\hline
\end{tabular}

Berdasarkan Tabel 1 dapat dilihat, bila data dikelompokkan menjadi tiga bagian, maka yang mempunyai skor data variabel hasil belajar IPA kelompok eksperimen (kelas VIIA) yang tinggi ada 6 siswa (33,33\%) dengan nilai antara 90 99; menengah ada 10 siswa (55,55\%) dengan nilai antara $80-89$; dan terendah ada 2 siswa (11,11\%) dengan nilai antara $75-79$.

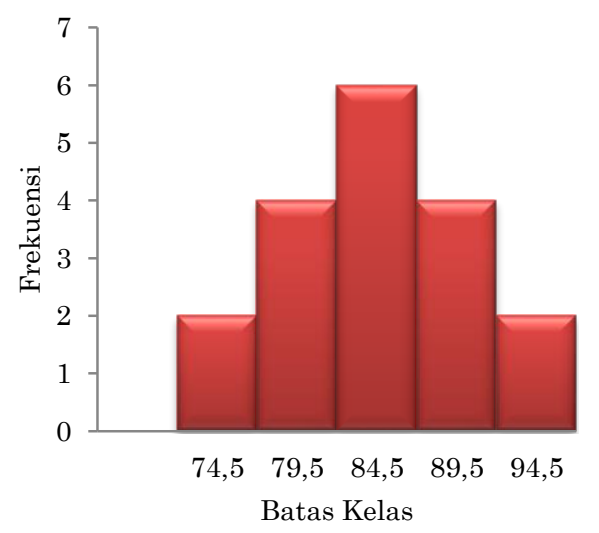

Gambar 1. Histogram data hasil belajar

IPA siswa kelompok eksperimen

Pada Gambar 1 menunjukkan bahwa nilai batas kelas 84,5 terdapat 6 siswa memiliki nilai terbanyak dan disusul oleh masing-masing 4 siswa memiliki nilai batas kelas 79,5 dan 89,5 serta masing-masing 2 siswa memiliki nilai batas kelas 74,5 dan 94,5.

Data hasil belajar IPA kelompok kontrol (kelas VIIB) menunjukkan bahwa skor tertinggi adalah 85 dan skor terendah 65. Berdasarkan data tersebut juga didapatkan harga harga rata-rata 73,89 dan simpangan baku 5,30. Distribusi frekuensi data variabel hasil belajar IPA kelompok kontrol (kelas VIIB) disajikan dalam Tabel 2, sedangkan histogramnya dapat dilihat pada Gambar 2 .

Tabel 2. Distribusi frekuensi data hasil belajar IPA siswa kelompok kontrol

\begin{tabular}{lllll}
\hline Kelas & $\begin{array}{l}\text { Interval } \\
\text { kelas }\end{array}$ & $\begin{array}{l}\text { Batas } \\
\text { kelas }\end{array}$ & $\begin{array}{l}\text { Frekuensi } \\
\text { absolut }\end{array}$ & $\begin{array}{l}\text { Frekuensi } \\
\text { relatif }\end{array}$ \\
\hline 1 & $65-69$ & 64,5 & 2 & 11,11 \\
2 & $70-74$ & 69,5 & 5 & 27,78 \\
3 & $75-79$ & 74,5 & 7 & 38,89 \\
4 & $80-84$ & 79,5 & 3 & 16,67 \\
5 & $85-89$ & 84,5 & 1 & 5,56 \\
\hline Jumlah & & & 18 & $100 \%$ \\
\hline
\end{tabular}

Berdasarkan Tabel 2 dapat dilihat, bila data dikelompokkan menjadi tiga 
bagian, maka yang mempunyai skor data variabel hasil belajar IPA kelompok kontrol (kelas VIIB) yang tinggi ada 4 siswa (22,23\%) dengan nilai antara $80-$ 89; menengah ada 12 siswa (66,67\%) dengan nilai antara $70-79$; dan terendah ada 2 siswa $(11,11 \%)$ dengan nilai antara $65-69$.

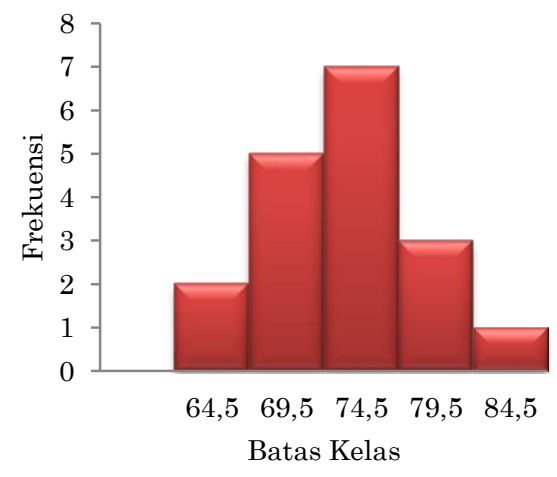

Gambar 2. Histogram data hasil belajar

IPA siswa kelompok kontrol

Pada Gambar 2 menunjukkan bahwa nilai batas kelas 74,5 terdapat 7 siswa memiliki nilai terbanyak dan disusul oleh 5 siswa memiliki nilai batas kelas $69,5,3$ siswa memiliki nilai batas kelas 79,5 dan 2 siswa memiliki nilai batas kelas 64,5 serta 1 siswa memiliki nilai batas kelas 84,5.

Berdasarkan pengujian persyaratan analisis yakni pengujian normalitas data dengan menggunakan uji Lilliefors dan pengujian homogenitas varians dengan menggunakan uji varians terbesar banding varians terkecil, data yang diperoleh untuk kelas eksperimen dan kelas kontrol berasal dari populasi atau data yang berdistribusi normal, serta varians dari kedua populasi asal sampel penelitian adalah homogen. Oleh karena itu, pengujian dilanjutkan dengan uji hipotesis penelitian.

Hipotesis yang akan diuji dalam penelitian ini adalah terdapat pengaruh model pembelajaran berbasis proyek terhadap peningkatan hasil belajar IPA siswa di SMP Advent Tondano. Untuk menguji hipotesis tersebut berarti membandingkan rata-rata skor hasil belajar IPA kelompok eksperimen yang diajar dengan model pembelajaran berbasis proyek lebih tinggi dibandingkan rata-rata hasil belajar IPA kelompok kontrol yang diajar tanpa model pembelajaran berbasis proyek, maka rumus yang sesuai adalah uji t.

Berdasarkan perhitungan pengujian hipotesis penelitian, diperoleh thitung sebesar 5,063. Berdasarkan tabel distribusi t pada $\alpha=0,05$ dengan derajat kebebasan $\mathrm{n}_{1}+\mathrm{n}_{2}-2=18+18-2=34$ maka diperoleh $t_{\text {tabel }}$ senilai 2,050. Jadi $t_{\text {hitung }}$ lebih besar dari ttabel, yaitu thitung $=$ $5,063>t_{\text {tabel }}=2,050$. Berdasarkan kriteria pengujian jika thitung lebih besar dari tabel (thitung $>$ ttabel$_{\text {) }}$ maka $\mathrm{H}_{0}$ ditolak yang berarti $\mathrm{H}_{\mathrm{a}}$ diterima, yang artinya ratarata skor hasil belajar IPA kelompok eksperimen yang diajar dengan model pembelajaran berbasis proyek lebih tinggi dibandingkan rata-rata hasil belajar IPA kelompok kontrol yang diajar tanpa model pembelajaran berbasis proyek. Dengan demikian, hasil penelitian menunjukkan bahwa penggunaan model pembelajaran berbasis proyek dapat meningkatkan hasil belajar IPA siswa kelas VII SMP Advent Tondano.

\section{Pembahasan}

Hasil penelitian ini mengungkapkan bahwa terdapat perbedaan hasil belajar IPA siswa kelas VII SMP Advent Tondano. Perbedaan nilai rerata hasil belajar IPA kedua kelas tersebut disebabkan karena kelompok eksperimen (kelas VIIA) diajar dengan menggunakan model pembelajaran berbasis proyek sedangkan pada kelompok kontrol (kelas VIIB) diajar tanpa menggunakan model pembelajaran berbasis proyek. Hal ini dapat dilihat dari nilai data variabel hasil belajar IPA siswa (kelas VIIA) menunjukkan bahwa skor tertinggi adalah 95 dan skor terendah 75 . Berdasarkan data tersebut juga didapatkan harga rata-rata 85 dan simpangan baku 5,94. Bila data dikelompokkan menjadi tiga bagian, maka yang mempunyai skor data variabel hasil belajar IPA kelompok eksperimen (kelas VIIA) yang tinggi ada 6 siswa (33,33\%) dengan nilai antara 90 - 99; menengah ada 10 siswa (55,55\%) dengan nilai antara 80 - 89; dan terendah ada 2 
siswa (11,11\%) dengan nilai antara 75 79 .

Nilai data variabel hasil belajar IPA siswa (kelas VIIB) menunjukkan bahwa skor tertinggi adalah 85 dan skor terendah 65. Berdasarkan data tersebut juga didapatkan harga harga rata-rata 73,89 dan simpangan baku 5,30. Bila data dikelompokkan menjadi tiga bagian, maka yang mempunyai skor data variabel hasil belajar IPA kelompok kontrol (kelas VIIB) yang tinggi ada 4 siswa (22,23\%) dengan nilai antara 80 - 89; menengah ada 12 siswa $(66,67 \%)$ dengan nilai antara 70 - 79; dan terendah ada 2 siswa (11,11\%) dengan nilai antara $65-69$.

Hasil pengujian hipotesis penelitian dengan menggunakan analisis statistik uji-t menunjukkan bahwa penggunaan model pembelajaran berbasis proyek dalam proses pembelajaran IPA sangat efektif untuk meningkatkan hasil belajar IPA siswa kelas VII SMP Advent Tondano.

Hasil belajar kelompok eksperimen (kelas VIIA) rata-ratanya yaitu 85 lebih baik dibandingkan rata-rata hasil belajar kelompok kontrol (kelas VIIB) yaitu 73,89. Hal ini disebabkan karena kelompok eksperimen (kelas VIIA) diajar dengan penerapan model pembelajaran berbasis proyek sehingga hasil belajar IPA siswa kelompok tersebut lebih baik dibandingkan kelompok kontrol (kelas VIIB). Untuk itu agar mencapai hasil belajar yang optimal dan baik pada pembelajaran IPA siswa di SMP Advent Tondano khususnya pada siswa Kelas VII, model pembelajaran berbasis proyek dapat diterapkan sebagai alternatif model pembelajaran.

Berdasarkan hasil yang diperoleh, penerapan model pembelajaran berbasis proyek dapat meningkatkan motivasi siswa untuk belajar materi pencemaran lingkungan, dimana tujuan yang diharapkan dari materi ini yaitu siswa dengan penuh percaya diri mampu menjelaskan penyebab terjadinya pencemaran lingkungan, siswa secara mandiri mampu menyebutkan dengan teliti bahaya bahan kimia rumah tangga terhadap lingkungan air, dan siswa penuh tanggung jawab mampu menjelaskan efek samping dari pencemaran lingkungan, serta siswa secara mandiri mampu menyebutkan upaya penanggulangan dari pencemaran lingkungan.

Hasil penelitian ini sejalan dengan beberapa hasil penelitian terdahulu yang relevan, diantaranya penelitian yang dilakukan oleh Sastrika, Sadia \& Muderawan (2013), dimana hasil penelitian menemukan bahwa penerapan model pembelajaran berbasis proyek mampu memberikan pemahaman konsep kimia yang lebih baik dibandingkan dengan model pembelajaran konvensional. Sejalan juga dengann penelitian yang dilakukan Arimbawa, Sadia \& Tika (2013), yang menemukan bahwa terdapat perbedaan kemampuan pemecahan masalah antara kelompok siswa yang belajar dengan model pembelajaran berbasis proyek dan konvensional. Siswa yang belajar dengan model pembelajaran berbasis proyek memiliki kemampuan pemecahan masalah lebih baik dibandingkan siswa yang mengikuti model pembelajaran konvensional. Penelitian lainnya yang sejalan yakni hasil penelitian Dewi \& Peniati (2012), yang menemukan bahwa pembelajaran melalui penugasan proyek dapat mengoptimalkan aktivitas dan hasil belajar siswa hingga mencapai ketuntasan KKM sebesar 100\%.

\section{KESIMPULAN}

Kesimpulan yang diperoleh dari penelitian ini yaitu terdapat pengaruh model pembelajaran berbasis proyek terhadap peningkatan hasil belajar IPA siswa di SMP Advent Tondano.

\section{DAFTAR PUSTAKA}

Amanda, N. W. Y., Subagia, I. W., \& Tika, I. N. (2014). Pengaruh Model Pembelajaran Berbasis Proyek Terhadap Hasil Belajar IPA Ditinjau Dari Self Efficacy Siswa. Jurnal Pendidikan dan Pembelajaran IPA Indonesia, 4(1).

Arimbawa, P., Sadia, I. W., \& Tika, I. N. (2013). Pengaruh Model Pembelajaran Berbasis Proyek (MPBP) Terhadap Kemampuan Pemecahan Masalah IPA Siswa SMP Dilihat Dari Motivasi 
Berprestasi. Jurnal Pendidikan dan Pembelajaran IPA Indonesia, 3(1).

Dewi, A. P., \& Peniati, E. (2012). Penugasan Proyek Untuk Mengoptimalkan Aktivitas Dan Hasil Belajar Siswa. Journal of Biology Education, 1(1).

Dimyati \& Mudjiono. (2006). Belajar dan Pembelajaran. Jakarta: PT. Rineka Cipta.

Grant, M. M. (2002). Getting A Grip of Project Based Learning: Theory, Cases and Recomandation. North Carolina: Meredian A Middle School Computer Technologies. Journal, 5, 10-34.

Rati, N. W., Kusmaryatni, N., \& Rediani, N. (2017). Model Pembelajaran Berbasis Proyek, Kreativitas Dan Hasil Belajar Mahasiswa. JPI (Jurnal Pendidikan Indonesia), 6(1), 60-71.

Sani, R. A. (2014). Pembelajaran Saintifik Untuk Implementasi Kurikulum 2013. Jakarta: Bumi Aksara.

Sastrika, I. A. K., Sadia, W., \& Muderawan, I. W. (2013). Pengaruh Model Pembelajaran Berbasis Proyek Terhadap Pemahaman Konsep Kimia Dan Keterampilan Berpikir Kritis. Jurnal Pendidikan dan Pembelajaran IPA Indonesia, 3(2).

Sugiyono. (2011). Metode Penelitian Kuantitaif Kualitatif dan $R$ \& D. Bandung: Alfabeta.

Tumewu, W. A., Wulan, A. R., \& Sanjaya, Y. (2017, May). Comparison between project-based learning and discovery learning toward students' metacognitive strategies on global warming concept. In AIP Conference Proceedings (Vol. 1848, No. 1, p. 060013). AIP Publishing LLC. 